\title{
Socio-medical aspects of oropharyngeal manifestations in the context of the current pandemic
}

Dr Campeanu Adriana Teodora, PhD student, Ovidius University of Constanta

Prof. Mihaela Rus, Phd, Ovidius University of Constanta

*Associate Professor Petcu Lucian Cristian, PhD, Ovidius University of Constanta, Faculty of

Dental Medicine, Biophysics \& Biostatistics

Associate Professor Irina Magdalena Dumitru, PhD, Ovidius University of Constanta

*Corresponding author, petculucian@univ-ovidius.ro

\begin{abstract}
The manifestations occurring at the oropharyngeal level after the onset of the Covid 19 disease represent a current issue in national and international research.

This study aims to emphasize the importance of understanding these manifestations and to correlate them with other general chronic diseases, as well as the impact of immunosuppression in the Covid 19 context.

The appearance of changes in the sense of taste and smell in the case of patients with Covid is a novelty in viral infections.
\end{abstract}

Keywords: oropharyngeal manifestations, Covid 19, bleeding gums, changes in sense of taste and smell.

\section{Introduction}

The Coronavirus disease (COVID-19) is an infectious disease caused by a newly discovered ${ }^{1}$ coronavirus in early 2020.

In early 2020, after an outbreak in December 2019 in China, the World Health Organization identified SARS-CoV-2 as a new type of coronavirus. The outbreak spread rapidly throughout the entire world ${ }^{2}$.

SARS-CoV-2 is one of seven types of coronavirus, including those that cause severe illness, such as the Middle East Respiratory Syndrome (MERS) and Severe Acute Respiratory Syndrome (SARS). The other coronaviruses cause most of the respiratory viroses which affect us throughout the year; however, they are not a serious threat to healthy people ${ }^{3}$.

Most people infected with the COVID-19 virus will have mild to moderate respiratory illnesses and recover without requiring special treatment. The elderly and those with underlying medical

\footnotetext{
1 World Health Organization: "Coronavirus disease (COVID-19) advice for the public", "Coronavirus Infections", "Middle East respiratory syndrome coronavirus (MERS-CoV)", "Naming the coronavirus disease (COVID-19) and the virus that causes it", "Novel Coronavirus (2019nCoV) Situation Report - 11," "Novel Coronavirus (2019-nCoV) Situation Report - 22". "Q\&A on coronaviruses (COVID-19)". "Q\&A: Similarities and differences - COVID-19 and influenza", "Draft landscape of COVID-19 candidate vaccines - 20 April 2020", "Tobacco and waterpipe use increases the risk of suffering from COVID-19".

${ }^{2}$ European Centre for Disease Prevention and Control. Novel coronavirus disease 2019 (COVID-19) pandemic: increased transmission in the EU/EEA and the UK-sixth update -12 March 2020. Stockholm: ECDC; 2020.

${ }^{3}$ Idem.
} 
conditions, such as cardiovascular disease, diabetes, chronic respiratory disease and cancer, are more likely to develop serious illnesses ${ }^{4}$.

A study conducted in China in the first months from the onset of the pandemic on 103 COVID19 cases found two strains, which researchers called L and S. The S type was older, but the L type was more common in the early stages of the outbreak. They believe that one can cause more illness than the other, but they are still working on what it all means.

At the same time, it is normal for a virus to change or mutate since it infects people and this virus did so. There are several variants named after the regions in which they were first discovered; however, they have now spread to other areas and countries ${ }^{5}$.

The COVID-19 virus is spread mainly by saliva droplets or respiratory secretions when an infected person coughs or sneezes ${ }^{6}$.

The main symptoms include fever, cough, shortness of breath, breathing problems, fatigue, chills, sometimes with tremors, muscle aches, headache, sore throat, nasal congestion, loss of sense of smell or taste, nausea, diarrhea.

The virus can cause, in cases of complications, pneumonia, respiratory failure, heart disorders, liver disorders, septic shock and death. Many COVID-19 complications can be caused by a condition known as cytokine release syndrome or cytokine storm. This happens when an infection causes your immune system to flood your bloodstream with inflammatory proteins called cytokines. They destroy tissues and organs.

Breathing problems or difficulty breathing, chest pain or constant pressure, confusion, disorientation, cyanotic lips or face are other signs and symptoms encountered. Strokes have been reported in some people with COVID- $19^{7}$.

Some oral manifestations have been observed in patients with COVID-19. However, there is still the question as to whether these lesions are due to the coronavirus infection or to secondary manifestations resulting from the patient's systemic condition ${ }^{8}$.

\footnotetext{
4 World Health Organization: "Coronavirus disease (COVID-19) advice for the public", "Coronavirus Infections," "Middle East respiratory syndrome coronavirus (MERS-CoV)", "Naming the coronavirus disease (COVID-19) and the virus that causes it", "Novel Coronavirus (2019nCoV) Situation Report - 11", "Novel Coronavirus (2019-nCoV) Situation Report - 22". "Q\&A on coronaviruses (COVID-19)". "Q\&A: Similarities and differences - COVID-19 and influenza", "Draft landscape of COVID-19 candidate vaccines - 20 April 2020", "Tobacco and waterpipe use increases the risk of suffering from COVID-19".

${ }^{5}$ European Centre for Disease Prevention and Control. Novel coronavirus disease 2019(COVID-19) pandemic: increased transmission in the EU/EEA and the UK-sixth update -12 March 2020. Stockholm: ECDC; 2020.

6 World Health Organization: "Coronavirus disease (COVID-19) advice for the public", "Coronavirus Infections", "Middle East respiratory syndrome coronavirus (MERS-CoV)", "Naming the coronavirus disease (COVID-19) and the virus that causes it", "Novel Coronavirus (2019nCoV) Situation Report - 11", "Novel Coronavirus (2019-nCoV) Situation Report - 22", "Q\&A on coronaviruses (COVID-19)", "Q\&A: Similarities and differences - COVID-19 and influenza", "Draft landscape of COVID-19 candidate vaccines - 20 April 2020", "Tobacco and waterpipe use increases the risk of suffering from COVID-19".

${ }^{7}$ European Centre for Disease Prevention and Control. Novel coronavirus disease 2019(COVID-19) pandemic: increased transmission in the EU/EEA and the UK-sixth update -12 March 2020. Stockholm: ECDC; 2020.

${ }^{8}$ Juliana Amorim dos Santos, Ana Gabriela Costa Normando, Rainier Luiz Carvalho da Silva, Allan Christian Cembranel, Alan Roger Santos-Silva, Eliete Neves Silva Guerra, Oral mucosal lesions in a COVID-19 patient: New signs or secondary manifestations?, International Journal of Infectious Diseases, June, 2020, https://www.ijidonline.com/article/S1201-9712(20)30447-1/fulltext
} 
According to a recent study, the most common oral manifestations in people with COVID-19 which we obtain after conducting a search are: salivary gland disorders, xerostomia, changes in sense of taste and smell and lesions of the oral mucosa'.

In patients with COVID-19 we should consider the presence of oral signs and symptoms, including dysgeusia, petechiae, candidiasis, traumatic ulcers, HSV-1 infection, geographic tongue, aphtous stomatitis, among others. Thus, the importance of the clinical oral examination of patients with infectious diseases should be emphasized by research, given the needs for support, pain control and quality of life ${ }^{10}$.

\section{Material and method:}

This research took place between January 26, 2021 and February 26, 2021 and consisted of completing a questionnaire uploaded in Google Docs, which was completed online and disseminated across social networks and specific target groups.

The questionnaire on oropharyngeal manifestations in patients infected with COVID 19 is part of the scientific research of the doctoral thesis on Clinical manifestations in immunocompromised patients.

The questionnaire aimed to identify oropharyngeal manifestations in patients who were suffering from or who had suffered from the disease at the time of completing the questionnaire.

The questionnaire covers the following aspects: a part which includes general information, a part related to oral hygiene, past and present oropharyngeal manifestations and the relationship that the patient has or does not have with the dentist. Furthermore, in the last part, questions related to the oral manifestations during the Covid 19 infection and questions related to the change in the sense of taste and smell are addressed.

The general objective of the study was to detect the frequency of oropharyngeal manifestations and their presence in the COVID context.

Secondary objectives:

The existence of a correlation between oropharyngeal manifestations and cardiovascular and autoimmune diseases.

Research hypotheses:

\section{Hypothesis no. 1:}

Within the main objective we will investigate the oropharyngeal manifestations that patients presented before the onset of Covid 19 and the oropharyngeal manifestations that they had after the onset of COVID 19. We also aim to correlate the manifestations before and after the onset of the COVID pathology.

\section{Hypothesis no. 2:}

We aim to detect the most common oropharyngeal manifestations and to find a correlation before and after the onset of Covid 19.

\footnotetext{
${ }^{9}$ Hamed Mortazavi, Kosar Rezaeifar, Navid Nasrabadi, Oral Manifestations of Coronavirus Disease-19: A mini review, Scientific Foundation SPIROSKI, Skopje, Republic of Macedonia Open Access Macedonian Journal of Medical Sciences. 2020 Sep 25; 8(T1):286-289, p. 286

${ }^{10}$ Juliana Amorim dos Santos, Ana Gabriela Costa Normando, Rainier Luiz Carvalho da Silva, Renata Monteiro De Paula, Allan Christian Cembranel, Alan Roger Santos-Silva, Eliete Neves Silva Guerra, Oral mucosal lesions in a COVID-19 patient: New signs or secondary manifestations?, International Journal of Infectious Diseases, Volume 97, 2020,
} 


\section{Hypothesis no. 3:}

Identifying the correlation between the most common oropharyngeal manifestation and autoimmune and cardiovascular diseases.

\section{Hypothesis no. 4:}

Measuring the correlation between oropharyngeal manifestations and smoking, considering that smoking is a risk factor for the occurrence of several such conditions.

\section{Hypothesis no. 5:}

A study on the frequency of the lack in the sense of smell and taste in the patients from the sample and a comparative study between the change in the sense of smell and its evaluation on a scale from 0 to10.

\section{Description of the studied group:}

The questionnaire was answered by a number of 310 people with ages between 11 and 79 , the average age being 41 , of which women were more significant, 265 , respectively $85.5 \%$, compared to 45 men (14.5\%). The origin of the patients was urban - 277 (85.4\%), compared to rural - 33, respectively $10.6 \%$. This could also be due to the fact that internet and social networks access is more accessible to people in urban areas. The level of education is also a factor which adds value, namely: respondents with higher education are $264(79.4 \%)$, compared to those with secondary education - 64 $(20.6 \%)$.

From a medical point of view, $77(24.8 \%)$ of the Covid patients in the study also suffered from other chronic diseases, namely: 40 (12.9\%) - cardiovascular diseases, 23 (7.4\%) - autoimmune diseases, diabetes $-7(2.3 \%)$, respiratory diseases - $11(3.5 \%)$.

\section{Analysis and interpretation of results:}

In order to validate the research hypothesis no. 1, we will determine the frequency of each oropharyngeal manifestation they faced before Covid 19, namely the patients' answer to the question: What were the medical conditions you faced in the past? The results were as follows: oral candidiasis $11.3 \%$ - 35 patients, oral herpes 109 - 35.16\%, aphtous stomatitis $119-38.39 \%$, tongue infection 5 $1 \%$, tonsillitis $148-47.74 \%$, pharyngitis $133-42.90 \%$, teeth pain $225-72,58 \%$, bleeding gums 146 $47.10 \%$, pockets of pus $58-18.71 \%$, dental abscess $106-34.19 \%$, dental injuries $41-13$, 23\%, stains on teeth $60-19.35 \%$.

To the question At this moment are you facing oropharyngeal manifestations, the moment we are talking about being after the onset of COVID 19, we have the following results: oral candidiasis 4 - $1.29 \%$, oral herpes $6-1.94 \%$, aphtous stomatitis $11-3.55 \%$, tongue infection $1-0.32 \%$, tonsillitis 5 - $1.61 \%$, pharyngitis $15-4.84 \%$, teeth pain $35-11.29 \%$, bleeding gums $53-17.10 \%$, periodontal pockets $4-1.29 \%$, dental abscess $12-3.87 \%$, dental injuries $11-3.55 \%$, stains on teeth $27-8.71 \%$.

In support of the research hypothesis, we will draw a correlation between the presence of oropharyngeal manifestations before and after the onset of COVID 19. 
Table no. 1: Comparative analysis of the value and percentage data of oropharyngeal manifestations before and after COVID 19 and the corresponding ratio between the two frequencies.

\begin{tabular}{|l|l|l|l|l|l|l|l|l|l|}
\hline & $\mathbf{n 1}$ & $\mathbf{p 1}$ & $\mathbf{p 1}(\mathbf{\%})$ & $\mathbf{n 2}$ & $\mathbf{p 2}$ & $\mathbf{p 2}(\mathbf{\%})$ & $\mathbf{p 1 - p 2 ( \% )}$ & $\mathbf{z}$ & $\mathbf{p}$ \\
\hline Oral candidiasis & 35 & 0.1129 & $11.29 \%$ & 4 & 0.0129 & $1.29 \%$ & $10.00 \%$ & 5.128 & 0.000 \\
\hline Oral herpes & 109 & 0.3516 & $35.16 \%$ & 6 & 0.0194 & $1.94 \%$ & $33.23 \%$ & 10.642 & 0.000 \\
\hline Aphtous stomatitis & 119 & 0.3839 & $38.39 \%$ & 11 & 0.0355 & $3.55 \%$ & $34.84 \%$ & 10.655 & 0.000 \\
\hline Tongue infection & 5 & 0.0161 & $1.61 \%$ & 1 & 0.0032 & $0.32 \%$ & $1.29 \%$ & 1.641 & 0.101 \\
\hline $\begin{array}{l}\text { Amigdalitis/ } \\
\text { Tonsillitis }\end{array}$ & 148 & 0.4774 & $47.74 \%$ & 5 & 0.0161 & $1.61 \%$ & $46.13 \%$ & 13.321 & 0.000 \\
\hline Pharyngitis & 133 & 0.4290 & $42.90 \%$ & 15 & 0.0484 & $4.84 \%$ & $38.06 \%$ & 11.117 & 0.000 \\
\hline Teeth pain & 225 & 0.7258 & $72.58 \%$ & 35 & 0.1129 & $11.29 \%$ & $61.29 \%$ & 15.464 & 0.000 \\
\hline Bleeding gums & 146 & 0.4710 & $47.10 \%$ & 53 & 0.1710 & $17.10 \%$ & $30.00 \%$ & 8.000 & 0.000 \\
\hline Periodontal pockets & 58 & 0.1871 & $18.71 \%$ & 4 & 0.0129 & $1.29 \%$ & $17.42 \%$ & 7.229 & 0.000 \\
\hline Dental abscess & 106 & 0.3419 & $34.19 \%$ & 12 & 0.0387 & $3.87 \%$ & $30.32 \%$ & 9.617 & 0.000 \\
\hline Dental injuries & 41 & 0.1323 & $13.23 \%$ & 11 & 0.0355 & $3.55 \%$ & $9.68 \%$ & 4.347 & 0.000 \\
\hline Stains teeth & 60 & 0.1935 & $19.35 \%$ & 27 & 0.0871 & $8.71 \%$ & $10.65 \%$ & 3.816 & 0.000 \\
\hline
\end{tabular}

The table shows that there are statistically significant differences between the compared ratios, namely between the frequencies recorded before and after the onset of Covid. Between the ratio of patients who previously had a tongue infection $\mathrm{p}_{1}=0.0161(1.61 \%)$ and the ratio of patients who currently have a tongue infection $\mathrm{p}_{2}=0.0032(0.32 \%)$ it is considered that there are NOT statistically significant differences $(\mathrm{z}=1.641 ; \mathrm{p}=0.101>\alpha=0.05)$.

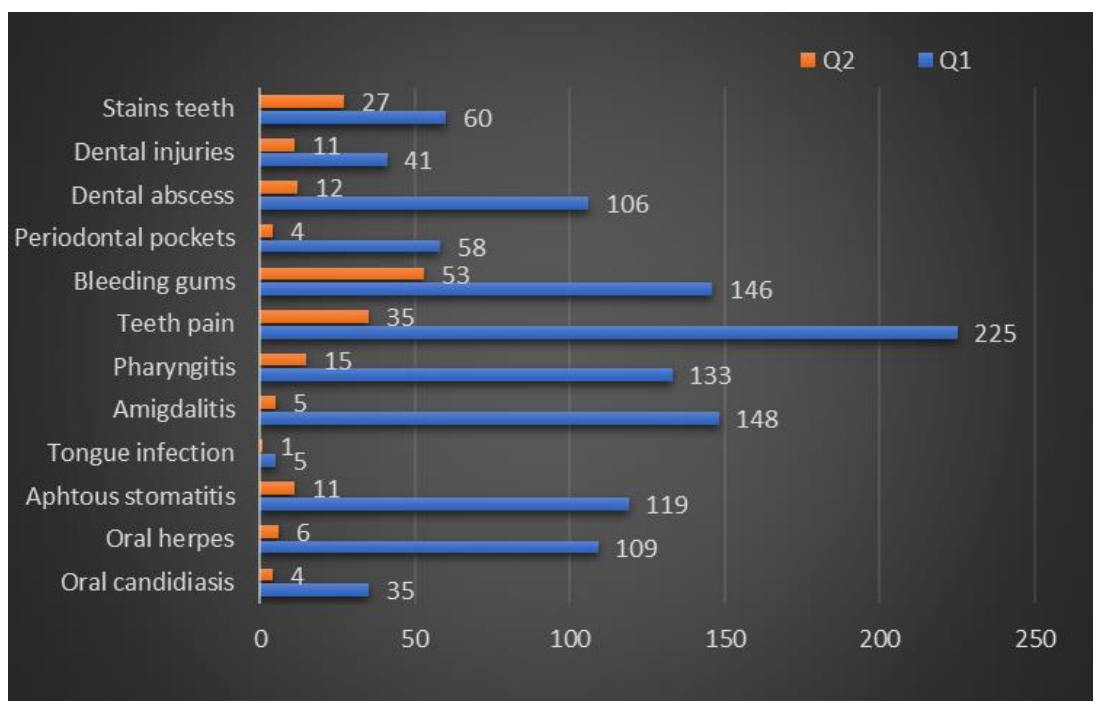

Fig. no. 1 Oropharyngeal manifestations before Covid 




Fig. no. 2 Oropharyngeal manifestations after the onset of Covid

We can notice that before COVID the most frequent manifestations were: teeth pain (72.58\%), then amigdalitis (47.74\%) and bleeding gums (47.10\%), while after the onset of Covid 19 the most common manifestations were bleeding gums (17.10\%) and teeth pain $(11.29 \%)$.

\section{Testing of hypothesis no. 2:}

Detection of the most frequent oropharyngeal manifestation and its correlation before and after the onset of COVID 19.

The most common manifestation in patients with COVID 19 is bleeding gums/gingival bleeding. Since this is one of the clinical signs of gingivitis and periodontitis we compared the frequency of gingival bleeding before and after the onset of Covid, as well as comparatively.

Table 2: Q3 - represents gingival bleeding before the onset of Covid 19 and Q4 - gingival bleeding after the onset of Covid 19.

\begin{tabular}{|c|c|c|c|c|c|c|c|c|c|}
\hline & \multicolumn{3}{|l|}{ Q3 } & \multicolumn{3}{|c|}{ Q4 } & \multirow[b]{2}{*}{$\begin{array}{l}\text { p1-p2 } \\
(\%)\end{array}$} & \multirow[b]{2}{*}{$\mathbf{z}$} & \multirow[b]{2}{*}{ p } \\
\hline & n1 & p1 & p1(\%) & n2 & p2 & p2(\%) & & & \\
\hline $\begin{array}{l}\text { Gingival } \\
\text { bleeding/bleeding } \\
\text { gums }\end{array}$ & 34 & 0.1097 & $10.97 \%$ & 67 & 0.2161 & $21.61 \%$ & $-10.65 \%$ & -3.589 & 0.000 \\
\hline
\end{tabular}


We notice that if before the onset of the disease the bleeding accounted for $10.97 \%$, after the onset it increased to $21.61 \%$, which means that the number of patients with gingival bleeding has doubled.

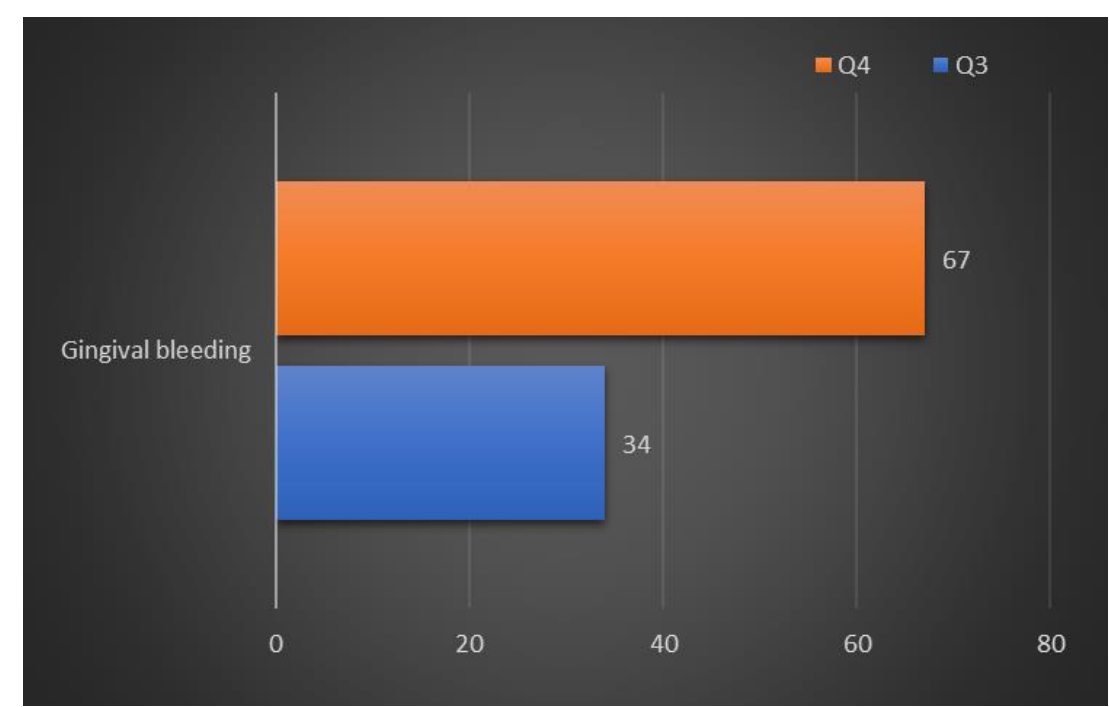

Figure no. 3: Graphical representation of gingival bleeding before the onset of Covid Q3

One can notice gingival bleeding in 34 people before the onset of Covid Q3 and in 67 people after the onset of Covid Q4.

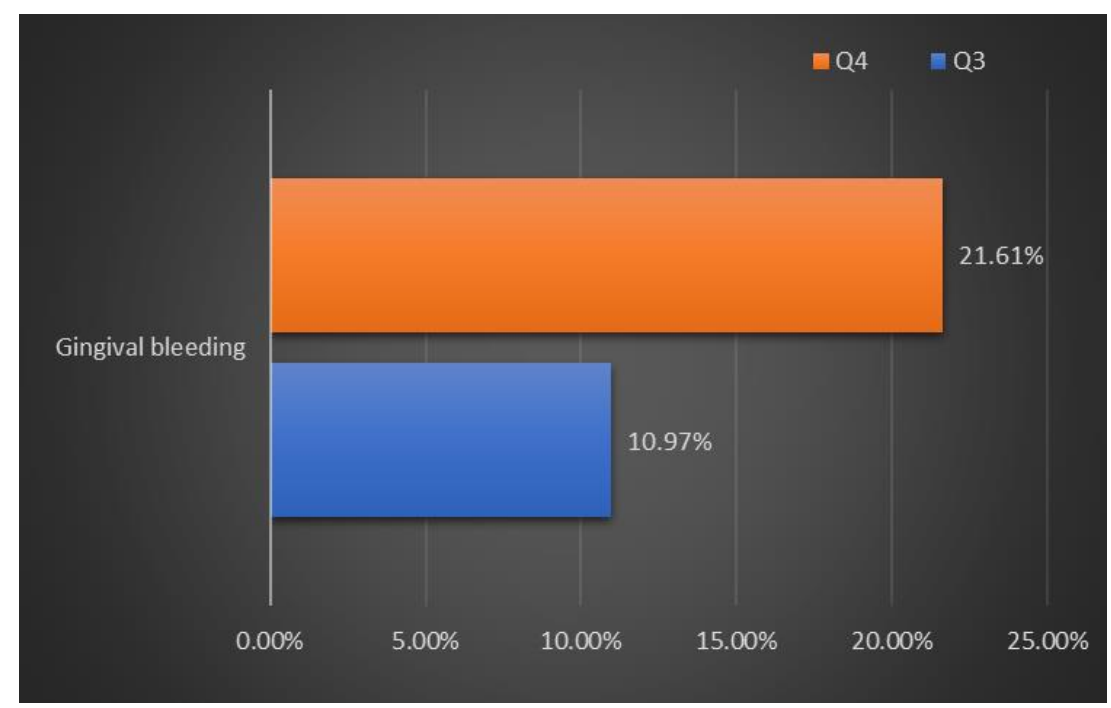

Figure no. 4: Comparative graphical representation of the percentage of gingival bleeding before the onset of Covid 19 - Q3 - 10.97\% and Q4 - after the onset - 21.61\%.

Between the ratio of patients who previously had bleeding $\mathrm{p}_{1}=0.1097(10.97 \%)$ and the ratio of patients who currently have bleeding $\mathrm{p}_{2}=0.2161(21.61 \%)$ it is considered that there are statistically significant differences $(\mathrm{z}=-3.589 ; \mathrm{p}<0.001<\alpha=0.05)$. 
Testing of hypothesis no. 3:

The correlation between the most common oropharyngeal manifestation: gingival bleeding and the most common chronic diseases.

To confirm the hypothesis, we correlated the presence of gingival bleeding in patients suffering from cardiovascular diseases, given that from all the chronic diseases, they had the highest frequency.

Table no. 3. Correlation between the presence of gingival bleeding and cardiovascular diseases

\begin{tabular}{|l|l|l|l|l|}
\hline \multicolumn{2}{|c|}{} & \multicolumn{2}{l|}{ Q6. Gingival bleeding } & \multirow{2}{*}{ Total } \\
\cline { 3 - 5 } \multicolumn{2}{|c|}{} & Yes & No & \\
\hline $\begin{array}{l}\text { Cardiovascular } \\
\text { diseases }\end{array}$ & Yes & $14(20.89 \%)$ & $26(10.69 \%)$ & $\mathbf{4 0}$ \\
\cline { 2 - 5 } Total & No & $53(79.1 \%)$ & $217(89.3 \%)$ & $\mathbf{2 7 0}$ \\
\hline
\end{tabular}

There is an association, a link between the observed bleeding and cardiovascular diseases: $\chi_{\text {calc }}^{2}=4,858, \mathrm{df}=1, \mathrm{p}=0.028<\alpha=0.05$ (Test $\chi^{2}$ of the association between two categorical variables).

Between the ratio of patients with cardiovascular diseases who showed bleeding $\mathrm{p}_{1}=0.2089$ (20.89\%) out of a total of 67 patients and the ratio of patients with cardiovascular diseases who did NOT bleed $\mathrm{p}_{2}=0.1069(10.69 \%)$ of the total of 243 patients there are statistically significant differences: $\mathrm{z}=2,204 ; \mathrm{p}=0.028<\alpha=0.05$ ( $Z$ test to compare two ratios).

The risk of bleeding in the group of patients with cardiovascular diseases is 2,205 times higher than the risk of bleeding in the group of patients without cardiovascular diseases: risk ratio OR = 2,205 , confidence interval $95 \% \mathrm{CI}=(1,078,4,510)$.

We made the following correlation between gingival bleeding and patients with autoimmune diseases, given that the underlying immunity can be a risk factor in the occurrence of gingivoperiodontal diseases.

Table no. 4 Correlation between gingival bleeding and patients with autoimmune diseases

\begin{tabular}{|l|l|l|l|l|}
\hline \multicolumn{2}{|c|}{} & \multicolumn{2}{l|}{ Q6. Gingival bleeding } & \multirow{2}{*}{ Total } \\
\cline { 3 - 5 } & & Yes & No & \\
\hline $\begin{array}{l}\text { Autoimmune } \\
\text { diseases }\end{array}$ & Yes & $10(14.92 \%)$ & $13(5.34 \%)$ & $\mathbf{2 3}$ \\
\cline { 2 - 5 } & No & $57(85.07 \%)$ & $230(94.65 \%)$ & $\mathbf{2 8 7}$ \\
\hline \multicolumn{2}{|l|}{ Total } & $\mathbf{6 7 ( 1 0 0 \% )}$ & $\mathbf{2 4 3 ( 1 0 0 \% )}$ & $\mathbf{3 1 0}$ \\
\hline
\end{tabular}

There is an association, a link between the observed bleeding and autoimmune diseases: $\chi_{\text {calc }}^{2}=$ $7.011, \mathrm{df}=1, \mathrm{p}=0.008<\alpha=0.05$ (Test $\chi 2$ of the association between two categorical variables).

Between the ratio of patients with autoimmune diseases who presented $\mathrm{p}_{1}=0.1492(14.92 \%)$ out of a total of 67 patients and the ratio of patients with autoimmune diseases who did NOT show bleeding $\mathrm{p}_{2}=0.0534(5.34 \%)$ out of a total of 243 patients There are statistically significant 
differences: $\mathrm{z}=2,648 ; \mathrm{p}=0.008<\alpha=0.05$ ( $Z$ test to compare two ratios). The risk of bleeding in the group of patients with autoimmune diseases is 3,104 times higher than the risk of bleeding in the group of patients without autoimmune diseases: risk ratio $\mathrm{OR}=3,104$, confidence interval $95 \% \mathrm{CI}$ $=(1,295,7,438)$.

\section{Testing the hypothesis:}

Study on the frequency of smokers in the total number of patients with Covid and the correlation between oropharyngeal manifestations in smokers suffering from Covid.

Table no.5 Values and frequencies of smokers in the total number of patients with Covid.

\begin{tabular}{|l|l|l|}
\hline Q5. Do you currently smoke? & $\mathbf{n}$ & $\mathbf{p}(\boldsymbol{\%})$ \\
\hline Yes & 75 & 24.2 \\
\hline No & 235 & 75.8 \\
\hline Total & 310 & 100.0 \\
\hline
\end{tabular}

We can notice that out of the total number of covid patients - 310, only 75 (24.2\%) are smokers, the difference being non-smokers - $235(75.8 \%)$.

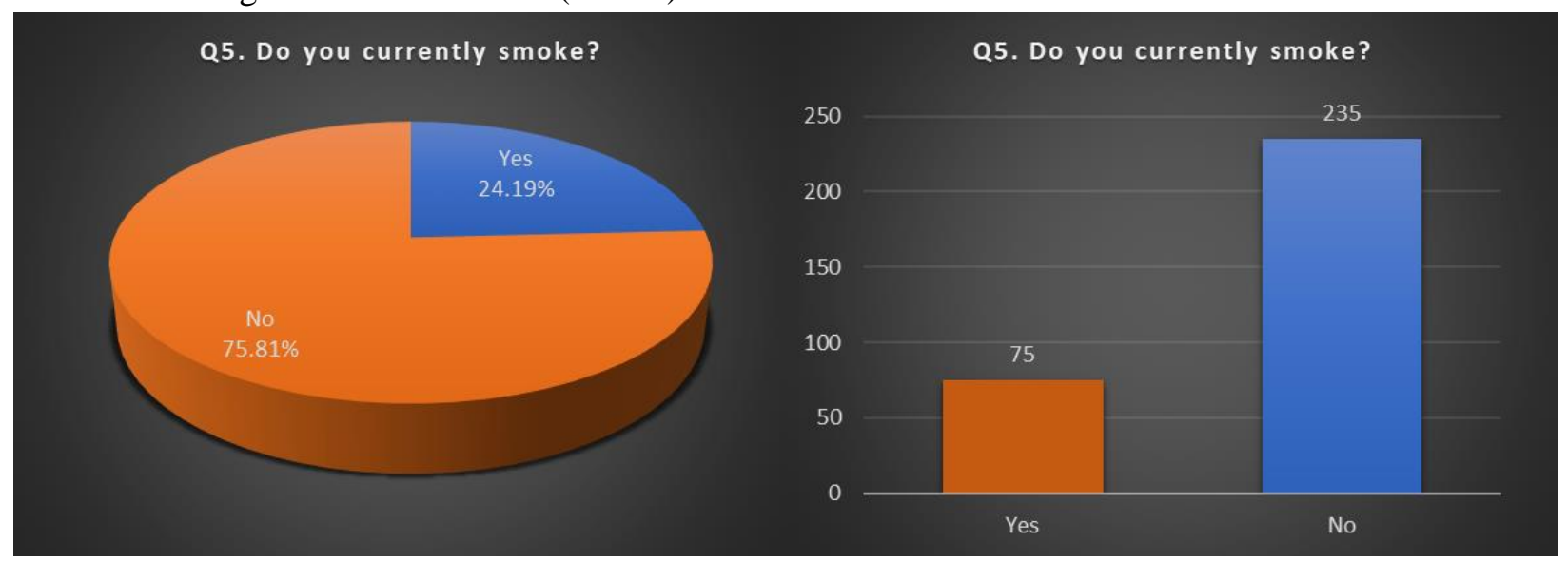

Figure no. 5: Graphical representation of the percentages and numerical values of smokers suffering from covid, in which yes represents the smokers and no represents the non-smokers.

Regarding the correlation between the occurrence of oropharyngeal manifestations in the percentage of smoking patients with Covid 19:

Table no. 5 and graphical representations 6 and 7 exemplify in value and percentage the ratios between the oropharyngeal manifestations in patients with Covid 19 who are smokers and non-smokers.

\begin{tabular}{|c|c|c|c|c|c|c|c|c|c|}
\hline & n1 & p1 & p1 $(\%)$ & n2 & p2 & p2(\%) & $\begin{array}{l}\text { p1-p2 } \\
(\%)\end{array}$ & $\mathbf{Z}$ & p \\
\hline Oral candidiasis & 2 & 0.0267 & $2.67 \%$ & 2 & 0.0085 & $0.85 \%$ & $1.82 \%$ & 1.213 & 0.225 \\
\hline Oral herpes & 1 & 0.0133 & $1.33 \%$ & 5 & 0.0213 & $2.13 \%$ & $-0.79 \%$ & -0.435 & 0.664 \\
\hline Aphtous stomatitis & 2 & 0.0267 & $2.67 \%$ & 9 & 0.0383 & $3.83 \%$ & $-1.16 \%$ & -0.474 & 0.635 \\
\hline Tongue infection & 0 & 0.0000 & $0.00 \%$ & 1 & 0.0043 & $0.43 \%$ & $-0.43 \%$ & -0.566 & 0.571 \\
\hline
\end{tabular}




\begin{tabular}{|l|l|l|l|l|l|l|l|l|l|} 
Amigdalitis & 3 & 0.0400 & $4.00 \%$ & 2 & 0.0085 & $0.85 \%$ & $3.15 \%$ & 1.885 & 0.059 \\
\hline Pharyngitis & 3 & 0.0400 & $4.00 \%$ & 12 & 0.0511 & $5.11 \%$ & $-1.11 \%$ & -0.389 & 0.697 \\
\hline Teeth pain & 10 & 0.1333 & $13.33 \%$ & 25 & 0.1064 & $10.64 \%$ & $2.70 \%$ & 0.642 & 0.521 \\
\hline Bleeding gums & 11 & 0.1467 & $14.67 \%$ & 42 & 0.1787 & $17.87 \%$ & $-3.21 \%$ & -0.642 & 0.521 \\
\hline Periodontal pockets & 2 & 0.0267 & $2.67 \%$ & 2 & 0.0085 & $0.85 \%$ & $1.82 \%$ & 1.213 & 0.225 \\
\hline Dental abscess & 5 & 0.0667 & $6.67 \%$ & 7 & 0.0298 & $2.98 \%$ & $3.69 \%$ & 1.442 & 0.149 \\
\hline Dental injuries & 2 & 0.0267 & $2.67 \%$ & 9 & 0.0383 & $3.83 \%$ & $-1.16 \%$ & -0.474 & 0.635 \\
\hline Teeth stains & 8 & 0.1067 & $10.67 \%$ & 19 & 0.0809 & $8.09 \%$ & $2.58 \%$ & 0.690 & 0.490 \\
\hline
\end{tabular}

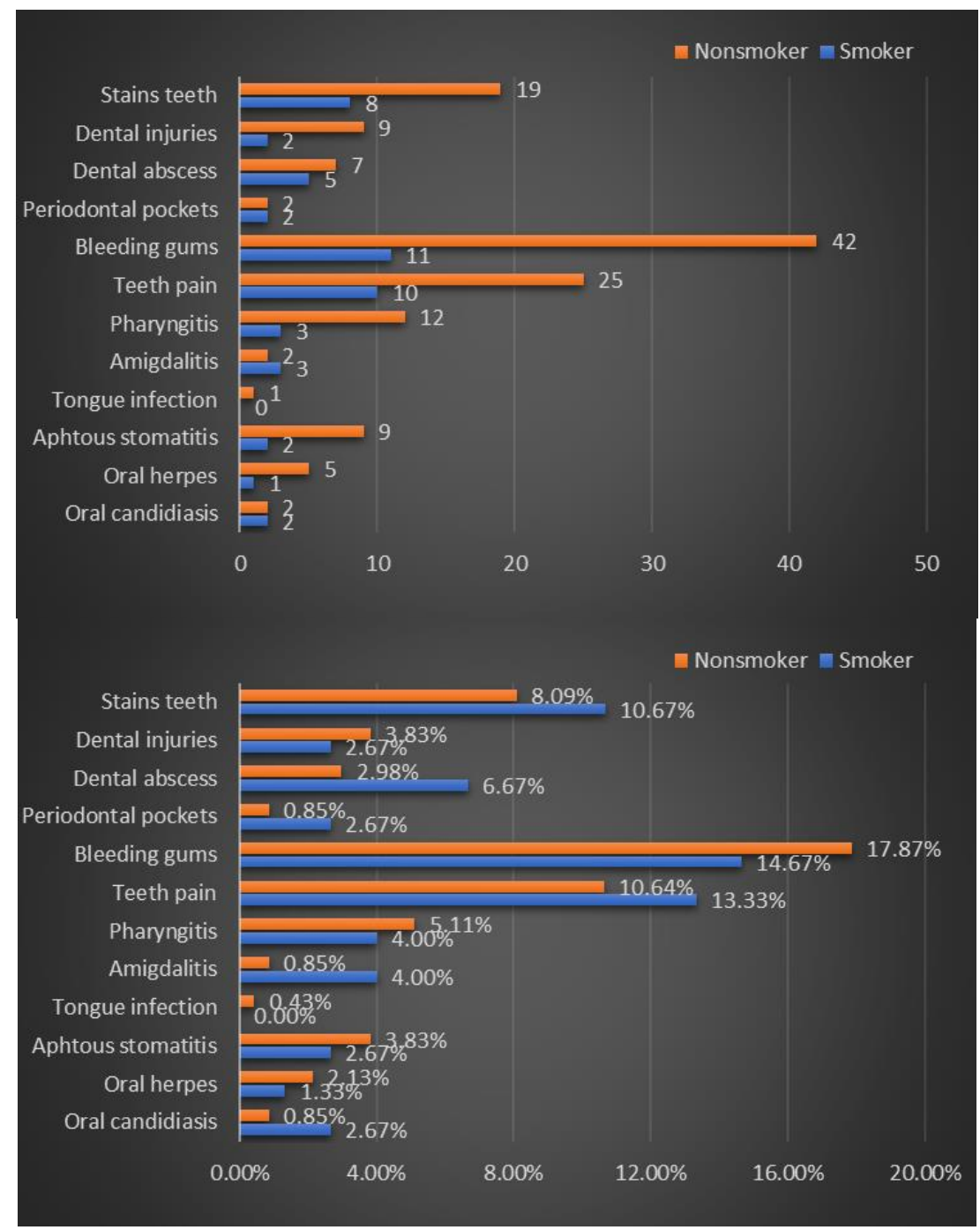

Figure no. 6 - Percentage and numerical representation of oropharyngeal manifestations in smokers and non-smokers

In all the cases, between the ratio of smoking patients who presented oropharyngeal manifestations and the ratio of non-smoking patients there are NOT statistically significant differences. 
Testing the hypothesis no. 5:

A study on the frequency of changes in the sense of smell and taste in patients (in the study) and a comparative study between the change in sense of smell and its evaluation on a scale from 0 to 10 .

Regarding the changes in the sense of taste, we conducted a comparative study of the changes in the sense of taste, namely: the changes in taste sensation of salty, sweet, spicy and sour.

Table 6- representing the frequency of changes in taste sensation of spicy

Q7. Do you feel a change in your sense of taste - Spicy?

\begin{tabular}{|ll|l|l|}
\hline & & Frequency & Percent \\
\hline Valid & Yes & 78 & 25.2 \\
& No & 232 & 74.8 \\
& Total & 310 & 100.0 \\
\hline
\end{tabular}

Table 7 -

representing the

frequency of

changes in taste

sensation of salty

Q8. Do you feel a change in your sense of taste - Salty?

\begin{tabular}{|ll|l|l|}
\hline & Frequency & Percent \\
\hline Valid & Yes & 85 & 27.4 \\
& No & 225 & 72.6 \\
& Total & 310 & 100.0 \\
\hline & Table 8 - \\
& representing the \\
& frequency of \\
& changes in taste \\
& sensation of sour
\end{tabular}

Q9. Do you feel a change in your sense of taste - Sour?

\begin{tabular}{|ll|l|l|}
\hline & Frequency & Percent \\
\hline Valid & Yes & 78 & 25.2 \\
& No & 232 & 74.8 \\
Total & 310 & 100.0 \\
\hline & Table 9 - \\
& representing the \\
& frequency of \\
& changes in taste \\
& sensation of \\
& sweet
\end{tabular}


Q10. Do you feel a change in your sense of taste Sweet?

\begin{tabular}{|ll|l|l|}
\hline & & Frequency & Percent \\
\hline Valid & Yes & 84 & 27.1 \\
& No & 226 & 72.9 \\
& Total & 310 & 100.0 \\
\hline
\end{tabular}

When asked about the changes in taste sensation, out of a total of 310 patients with Covid, 78 people (25.2\%) felt changes in taste sensation of spicy, 85 people $(27.4 \%)$ in taste sensation of salty, 78 people $(25.2 \%)$ in taste sensation of sour and 84 people $(27.1 \%)$ in taste sensation of sweet.

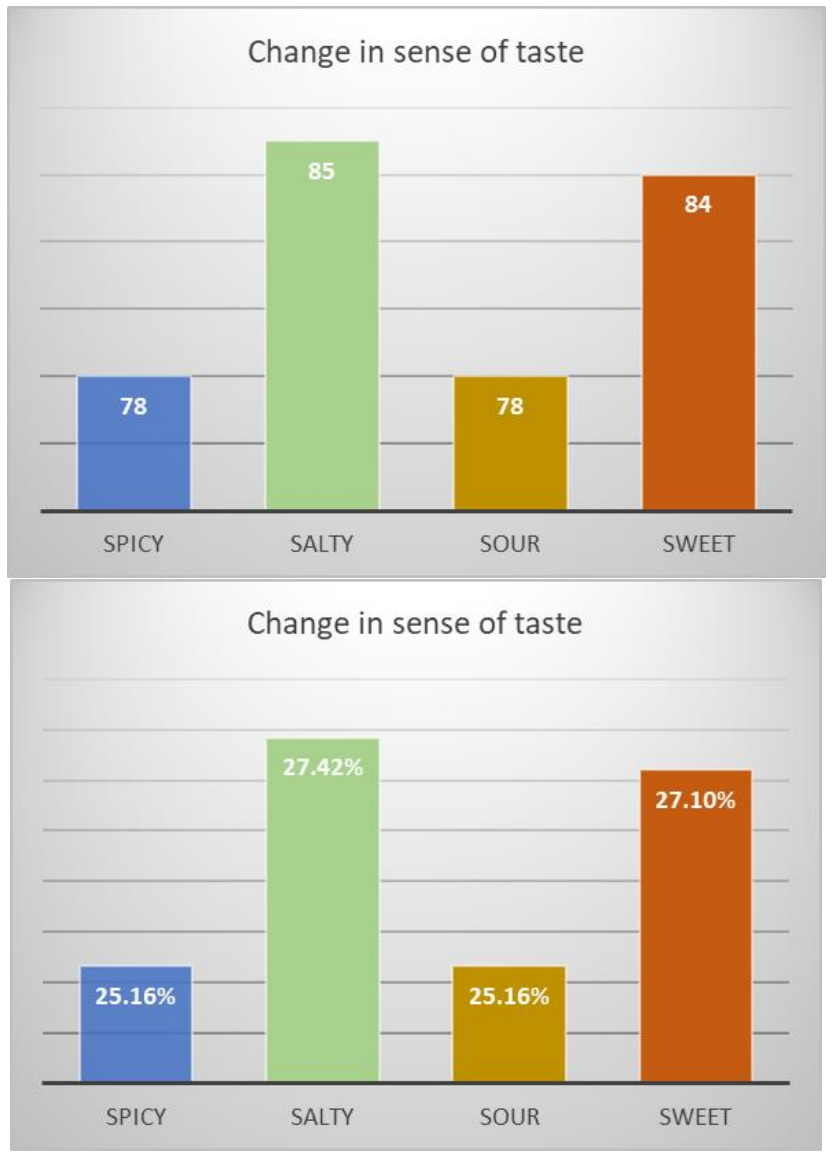

Figures no. 8 and 9 represent the value and percentage changes in the sense of taste in patients with Covid 19.

Regarding the changes in the sense of smell, in the Covid 19 context we analyzed the frequency of patients who lost their sense of smell from the total of those who answered and we correlated the lack of sense of smell with the rate of its loss on a scale from 0 to 10 . 
Table no. 10 representing the frequency of changes in sense of smell

Q11. Have you noticed a change in your sense of smell since COVID-19 onset?

\begin{tabular}{|ll|l|l|}
\hline & Frequency & Percent \\
\hline Valid & Yes & 212 & 68.4 \\
& No & 98 & 31.6 \\
& Total & 310 & 100.0 \\
\hline
\end{tabular}

We notice that out of 310 patients, 212 (68\%) had changes in the sense of smell and $98(31.6 \%)$ had no changes in their sense of smell.

Table no.11 representing the correlation between changes in smell on a scale from 0 to 10 .

\section{Descriptives}

\begin{tabular}{|c|c|c|c|}
\hline & \multicolumn{2}{|l|}{ Statistic } \\
\hline & & \multicolumn{2}{|c|}{$\begin{array}{l}\text { Q11. Have you noticed a change in your } \\
\text { sense of smell since COVID-19 onset? }\end{array}$} \\
\hline & & Yes (212) & No (98) \\
\hline \multirow{6}{*}{$\begin{array}{l}\text { Q12. Rate your sense of smell to } \\
\text { date, on a scale from } 0 \text { to } 10\end{array}$} & Mean & 7.22 & 9.44 \\
\hline & Median & 8 & 10 \\
\hline & Std. Deviation & 2.51 & 0.95 \\
\hline & Minimum & 1 & 5 \\
\hline & Maximum & 10 & 10 \\
\hline & $\begin{array}{l}\text { Range } \\
\text { Interquartile } \\
\text { Range }\end{array}$ & $\begin{array}{l}9 \\
3\end{array}$ & $\begin{array}{l}5 \\
1\end{array}$ \\
\hline
\end{tabular}

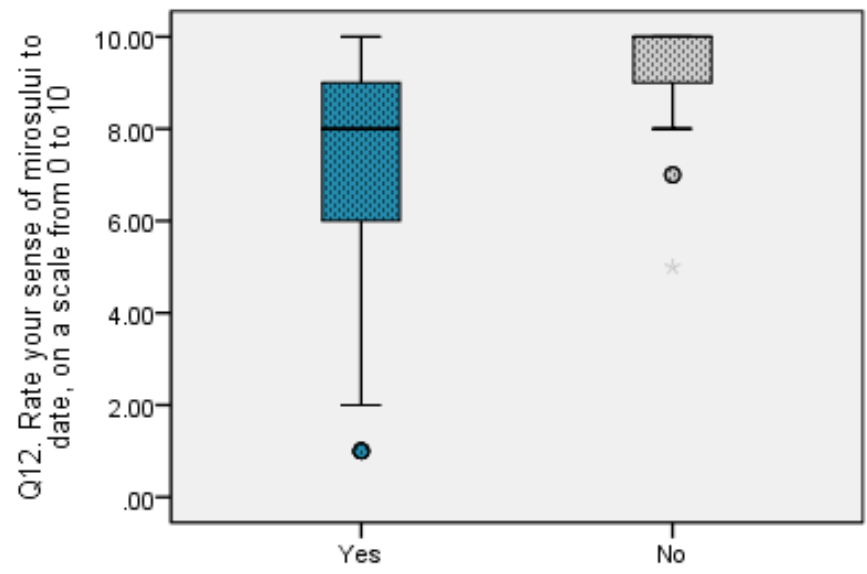

Q11. Have you noticed a change in your sense of smell since COVID-19 onset

Figure no. 10 Box-Plot graph of the rated scores on the sense of smell quality by patients who stated that the sense of smell was altered / unaltered 
Table no. 12 Mann-Whitney U Test

Hypothesis Test Summary

\begin{tabular}{|c|c|c|c|c|}
\hline & Null Hypothesis & Test & Sig. & Decision \\
\hline 1 & $\begin{array}{l}\text { The medians of Q6.5. Apreciati } \\
\text { simtul mirosului la dumneavoasta } \\
\text { acum, pe o scara de la } 0 \text { la } 10 \text { are } \\
\text { the same across categories of Q6. } \\
\text { 2. Vi sa alterat simtul mirosului de } \\
\text { cand s-a instalat COVID-19?. }\end{array}$ & $\begin{array}{l}\text { Independent- } \\
\text { Samples } \\
\text { Median Test }\end{array}$ & .000 & $\begin{array}{l}\text { Reject the } \\
\text { null } \\
\text { hypothesis. }\end{array}$ \\
\hline 2 & $\begin{array}{l}\text { The distribution of Q6.5. Apreciati } \\
\text { simtul mirosului la dumneavoasta } \\
\text { acum, pe o scara de la } 0 \text { la } 10 \text { is } \\
\text { the same across categories of } Q 6 \text {. } \\
\text { 2. Vi sa alterat simtul mirosului de } \\
\text { cand s-a instalat COVID-19?. }\end{array}$ & $\begin{array}{l}\text { Independent- } \\
\text { Samples Mann- } \\
\text { Whitney U Test }\end{array}$ & .000 & $\begin{array}{l}\text { Reject the } \\
\text { null } \\
\text { hypothesis. }\end{array}$ \\
\hline
\end{tabular}

Asymptotic significances are displayed. The significance level is .05 .

\begin{tabular}{|c|c|}
\hline 0 & 10 \\
\hline $\begin{array}{l}\mathrm{Vis} \\
\mathrm{Cov}\end{array}$ & since COVID-19' \\
\hline
\end{tabular}

The Mann-Whitney U test shows that the distribution of rated scores on the sense of smell quality by patients who stated that their sense of smell is altered is different statistically $(\mathrm{p}<0.001<\alpha=0.05)$ from the distribution of rated scores on the sense of smell quality by patients who stated that they do not have an altered smell. Also, the test comparing the median values of the sense of smell quality's scores shows that there are significant differences between their values $(\mathrm{p}<0.001<\alpha=0.05)$ depending on the investigated group, Yes / No.

\section{Conclusions:}

1. Regarding research hypothesis no. 1, we conclude that the oropharyngeal manifestations after the onset of Covid 19 are not more frequent than before the onset. The most common manifestation found in the Covid 19 context is gingival bleeding, which can be caused by a multitude of factors. Gingival bleeding is a sign of a gingival-periodontal disease whose local cause is the presence of the bacterial plaque accumulated due to poor oral hygiene. Along with gingival hypertrophy, spontaneous bleeding and while brushing are the elements that diagnose gingivitis.

In addition to local factors that can cause gingival bleeding, they can also occur in the context of general chronic diseases, such as diabetes, cardiovascular disease, immunosuppression. There were clear statistical differences between the ratios of patients who had oropharyngeal manifestations in favor of those before the onset of Covid, and one could only conclude that gingival bleeding is more common.

2. Regarding research hypothesis no. 2, we have shown that gingival bleeding doubled in the Covid 19 context, comparing gingival bleeding before and after the onset of the disease. If before Covid only 34 patients suffered from bleeding after the onset 67 were suffering from it.

3. Regarding research hypothesis no. 3, we have found out that the most common chronic diseases in patients with Covid are Cardiovascular diseases - 40 patients (12.9\%), 23 having autoimmune diseases $(7.4 \%)$.

The risk of bleeding in the Covid 19 group of patients with cardiovascular diseases is 2,205 times higher than the risk of bleeding in the group of Covid 19 patients without cardiovascular diseases. The risk of bleeding in the group of patients with autoimmune diseases is 3,104 times higher than the risk of bleeding in the group of patients without autoimmune diseases. 
We conclude that the risk of bleeding is influenced by pre-existing chronic diseases.

4. Regarding research hypothesis no. 4, on the frequency of smokers in the total number of patients with Covid and the correlation between oropharyngeal manifestations in smokers with Covid we conclude the following:

The number of smoking patients with Covid is lower than that of non-smokers. We cannot say that smoking is a favorable or a risk factor in contracting Covid. Furthermore, there is no correlation between the more frequent occurrence of oropharyngeal manifestations in smokers compared to nonsmokers in the Covid context.

5. Following the study on the frequency of change in sense of smell and taste in the patients of our study and the comparative study between the change in sense of smell and its evaluation on a scale from 0 to10 from hypothesis no. 5, we conclude that: Changes in the sense of taste occurred in $24 \%$ of patients, without a more frequent change in one of the tastes: spicy, salty, sour and sweet. Out of the total of 310 patients, 212 (68\%) had changes in their sense of smell and $98(31.6 \%)$ had no changes in their sense of smell.

The results of our studies directly contribute to the efforts of researchers around the world to fight SARS COV2 infection and to bring a novelty element to the research conducted so far, given that this is a new disease and that research is just commencing.

We emphasize the need for further studies on larger samples of surveyed patients combined with groups of objectively evaluated patients.

\section{REFERENCES}

[1.] European Centre for Disease Prevention and Control. Novel coronavirus disease 2019 (COVID19) pandemic: increased transmission in the EU/EEA and the UK-sixth update -12 March 2020. Stockholm: ECDC; 2020

[2.] Hamed Mortazavi, Kosar Rezaeifar, Navid Nasrabadi, Oral Manifestations of Coronavirus Disease-19: A mini -review, Scientific Foundation SPIROSKI, Skopje, Republic of Macedonia Open Access Macedonian Journal of Medical Sciences. 2020 Sep 25; 8 (T1): 286-289, International Journal of Infectious Diseases, Volume 97, 2020, pp. 326-328,

[3.] Juliana Amorim dos Santos, Ana Gabriela Costa Normando, Rainier Luiz Carvalho da Silva, Allan Christian Cembranel, Alan Roger Santos-Silva, Eliete Neves Silva Guerra, Oral mucosal lesions in a COVID-19 patient: New signs or secondary manifestations?, International Journal of Infectious Diseases, June, 2020, https://www.ijidonline.com/article/S1201-9712(20)30447$\underline{1 / \text { fulltext }}$

[4.] World Health Organization: "Coronavirus disease (COVID-19) advice for the public", "Coronavirus Infections", "Middle East respiratory syndrome coronavirus (MERSCoV)", "Naming the coronavirus disease (COVID-19) and the virus that causes it", "Novel Coronavirus (2019nCoV) Situation Report - 11", "Novel Coronavirus (2019-nCoV) Situation Report - 22". "Q\&A on coronaviruses (COVID-19)". "Q\&A: Similarities and differences COVID-19 and influenza", "Draft landscape of COVID-19 candidate vaccines - 20 April 2020", "Tobacco and waterpipe use increases the risk of suffering from COVID-19." 